\title{
ESPAÇO E QUALIDADE AMBIENTAL: ANÁLISE DE IMPACTOS EM UMA BACIA HIDROGRÁFICA AMAZÔNICA ${ }^{1}$
}

\section{Space And Environmental Quality: Analysis Of Impacts In An Amazonian Basin Hydrographic}

Waldemir Lima dos SANTOS ${ }^{2}$

\begin{abstract}
RESUMO
A preocupação com a qualidade ambiental e a falta de água potável vem sendo refletida nos debates e encontros realizados pelas diversas instituições nacionais e internacionais que lidam com a causa "meio ambiente". Questões como o manejo de recursos naturais no âmbito das bacias hidrográficas aliado às atividades humanas dá o tom de uma possível escassez, principalmente de recursos hídricos, nas próximas décadas, até mesmo na região amazônica. Com esse entendimento, o presente trabalho vem demonstrar os impactos ambientais ocasionados no canal principal da bacia hidrográfica do igarapé Judia (afluente da margem direita do rio Acre), abrangendo o trecho urbano da cidade de Rio Branco/AC, através de análise sócioambiental dos ocupantes dessa área.
\end{abstract}

Palavras-chave:

geossistema; recursos hídricos; impactos ambientais.

\begin{abstract}
The concern about the environmental quality and the drinking waters lock comes reflected from the debates and meeting fulfilled through diverse national and international institutions that manage the cause "environment". Questions as the manage of natural resources in the scope as the hydrographic basins allied to the human activities give the tone of a possible shortness, mainly, of hydric resources in the next decades, even to the Amazon region. With this understanding, the present work aims at demonstrating the caused environmental impacts in the main canal of the hydrographic basin of the water Judia stream (affluent of the right margim of the river Acre). Cover the urban stretch of the city of Rio Branco/AC aims at demonstrating, through social-environmental analysis of the occupants of this area.
\end{abstract}

Key-words:

geosystem; hydrics resources; environmental impacts.

1 Artigo elaborado a partir da dissertação de mestrado: O processo de urbanização e impactos ambientais em bacias hidrográficas - 0 caso do igarapé Judia - Acre - Brasil, defendida em 2005, junto ao Programa de Pós-Graduação da Universidade Federal do Acre/UFAC.

2 Professor Assistente do Departamento de Geografia da Universidade Federal do Acre - UFAC - Mestre em Ecologia e Manejo de Recursos Naturais. 


\section{INTRODUÇÃO}

No limiar do século XXI, emerge uma temática que reflete uma problemática nas médias e grandes cidades: a conciliação entre a qualidade ambiental e o incremento populacional. Diante disso, este trabalho tem por objetivo demonstrar os impactos ambientais negativos advindos da ocupação do espaço na bacia hidrográfica do igarapé Judia (AC), localizado no sudoeste da Amazônia Legal.

Reportar-se a transformação e (re)organização espacial é fazer um estudo detalhado do espaço onde se processam essas transformações, tanto de forma artificial (impostas pela humanidade) quanto pelos agentes naturais, entendidos aqui como geossistema.

Nessa perspectiva, há que situar as atividades humanas, no contexto devastador da natureza, como sendo as principais modificadoras das relações ecossistêmicas que discutem o papel do elemento humano nesta relação, incluindo-o como o único desequilibrador dos ecossistemas naturais, capaz de alterar a estrutura de espécies das comunidades e produzir enormes mudanças nos meios físicos e químicos do ambiente, pela adição de substâncias poluentes dos mais diversos tipos. Tais mudanças podem provocar roturas no equilíbrio dos ecossistemas que levam a prejuízos muitas vezes incontroláveis e irreversíveis, afetando até mesmo as possibilidades de sobrevivência da espécie humana (MAGALHÃES, 1982).

O caso da poluição dos mananciais que outrora eram rurais e hoje são considerados urbanos, em virtude do processo de urbanização, reflete bem este questionamento uma vez que a adição e o depósito de elementos químicos, advindos do lixo e das mais variadas fontes, são uma realidade, paradoxalmente, na região amazônica, alterando o comportamento desses ecossistemas, ocasionando impactos ambientais negativos.

A poluição atinge o seu auge quando a flora e a fauna aquática deixam de proliferar-se normalmente, chegando a apresentar incrementações em seu potencial biótico dada a contaminação. Nesse contexto, a humanidade também é ameaçada de morte diante da necessidade do consumo de água e alimento oriundos destes mananciais.

É a partir desse entendimento que analisamos e propomos respostas e soluções condizentes com a realidade posta, tentando inserir o homem como parte integrante da natureza, levando-se em consideração as transformações espaciais geradas e as causas desses impactos ambientais no igarapé Judia (AC).

Tais modelações e modificações espaciais levariam em conta os agentes determinadores e causadores da nova configuração, e seria necessário, um diagnóstico geral sobre as modificações ocorridas para uma explicação do fenômeno; em conseqüência, os agentes causadores seriam encontrados.

Assim, a pesquisa realizada possibilitou diagnosticar a mudança espacial e a relação conflituosa do homem versus natureza, considerando-se que a organização do espaço e sua transformação são resultado do equilíbrio dos fatores de dispersão e concentração em um dado momento da história desse espaço.

No caso em tela, a concentração populacional na área urbana de Rio Branco/AC traz consigo vários problemas ambientais, dentre os quais os desequilíbrios ecológicos advindos da má ocupação do espaço. No Gráfico 1, podemos observar o comportamento do crescimento populacional total, urbano e rural de Rio Branco (AC), desde 1970, e a perspectiva de aumento até 2030.

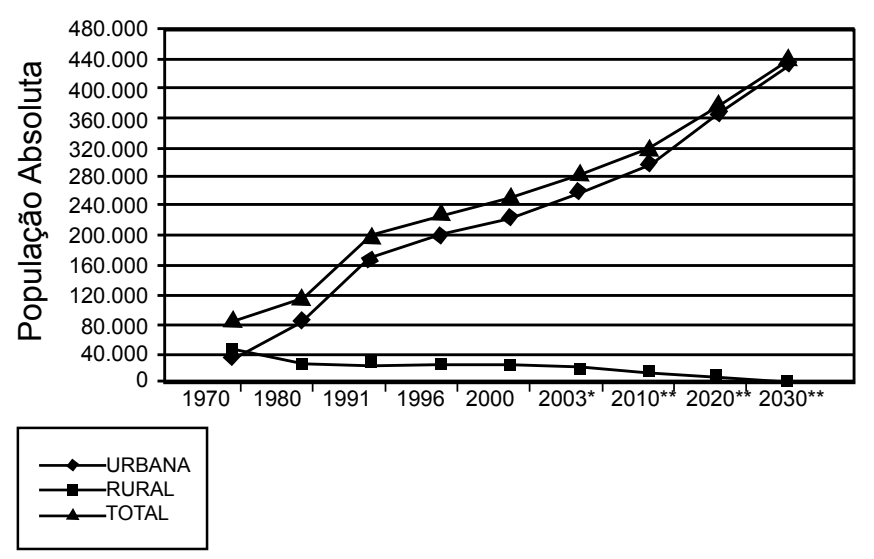

\section{GRÁFICO 1 - POPULAÇÃO ABSOLUTA, POR SITUAÇÃO DE DOMICÍLIO, DO MUNICÍPIO DE RIO BRANCO-AC E ESTIMATIVA PARA OS ANOS DE 2010/2020/2030}

FONTE: IBGE - Instituto Brasileiro de Geografia e Estatística * FUNASA - Fundação Nacional de Saúde

${ }^{* *}$ Estimativa populacional, a partir de regressão linear proposta por STEVENSON (1981).

Assim, o que de fato vem ocorrendo na área em estudo em relação à ocupação desenfreada tem raízes em um processo migratório campo-cidade, que levou a população da zona rural a procurar melhores condições de vida na cidade, desmatando e dando início às invasões de áreas rurais próximas dela, gerando mais tarde os bairros periféricos e a ocupação de fundos de vales, que constituem áreas de preservação permanentes, legalmente proibidas para ocupação pelo Código Florestal brasileiro. 
Em virtude disso, a saída de uma população expropriada da zona rural para os centros urbanos contribui para a concentração dessa massa populacional em uns poucos pontos privilegiados do espaço, pontos estes que lhe fornecessem o necessário para viver - a alimentação - tendo como alvo principal as margens dos igarapés, que ao longo do tempo, em conseqüência do processo de desmatamento e urbanização, tornaram-se praticamente igarapés urbanos com diversas moradias situadas às suas margens, fornecendo aos habitantes água e comida, através da pesca de subsistência.

Estes processos sociais, que vão desde a divisão de classes sociais até a ocorrência de novas alternativas de vida, criam funções e formas espaciais, além de atividades diversas e suas materializações no espaço. As formas de sobrevivência impostas pelo homem refletemse nas transformações observadas no espaço, através da ocupação inadequada em áreas que poderiam ser preservadas ou utilizadas racionalmente.

Para que haja a racionalização no uso dos recursos hídricos, faz-se necessário impor um mecanismo de gestão da bacia hidrográfica do igarapé Judia onde esteja presente a prática do manejo ambiental, impedindo a sua destruição. Não restam dúvidas de que, com o aumento populacional, as necessidades também aumentarão e surgirão novos padrões de consumo, juntamente com enormes problemas ambientais relacionados, principalmente, à poluição.

A urbanização exerce um papel duplicador em seus efeitos: ao mesmo tempo em que promove o bemestar das pessoas oriundas da zona rural, traz consigo o problema dos impactos ambientais ocasionados, principalmente, pela falta de informação necessária à preservação e conservação dos recursos naturais.

Mesmo estando inserido no interior da maior bacia hidrográfica do mundo, faz-se necessário refletir sobre as interferências da expansão das cidades. Nesse sentido, Tagnin e Magalhães (2001, p. 4) afirmam que:

(...) os padrões de expansão [urbanas] apresentam fortes repercussões ambientais, em especial sobre os mananciais de água, suprimindo-lhes os ecossistemas e as últimas reservas de vegetação natural e criando situações de escassez, mesmo em locais com grande disponibilidade natural. Seu potencial de interferência é particularmente agudo nas grandes cidades, onde todos os seus efeitos são multiplicados.

Na maioria dos casos, a atividade econômica está envolvida nesse processo de degradação e poluição ambiental. O próprio sistema produtivo de bens e capital gera pontos negativos quando do processo de urbani- zação, considerando que a saída de uma população da zona rural, constituindo-se no "êxodo rural", faz-se em decorrência de modificações na esfera econômica, seja em virtude de processos de mecanização agrícola, seja pela mudança do modelo econômico até então implantado - no nosso caso, da extração do látex para a atividade pecuarista.

O sistema produtivo tem exaurido grandes recursos do sistema natural (ecossistemas), deixando de haver uma compensação ou retroalimentação ao sistema natural daquilo que fora retirado/perdido à espoliação do sistema natural, através da extração de seus recursos, somam-se ainda mazelas da poluição, nas suas mais variadas formas. No caso em tela ficou evidenciada esta prática, uma vez que há uma parcela considerável da população que habita as margens dos igarapés; porém, o retorno a estas fontes vem em forma de lixo e poluentes (ALMEIDA et al. 1999).

É preocupante estudar meios para conter as agressões ambientais no tocante ao uso racional dos recursos hídricos, pensando sempre num futuro harmônico entre homem e natureza. Nesse compasso, a idéia de desenvolvimento sustentável estará sempre presente a fim de garantir a sobrevivência das espécies no futuro e definir uma política socioeconômica no presente que não venha de forma alguma prejudicá-las.

Com esse entendimento, pode-se considerar como componente do desenvolvimento sustentável qualquer atividade econômica que aumente o bem-estar social com a máxima quantidade de conservação de recursos e a mínima quantidade de degradação ambiental permitida dentro das limitações econômicas, sociais e tecnológicas (GARAY e DIAS, 2001).

Falar em degradação ambiental ou impacto ambiental é estar diante da capacidade humana de se autodestruir, agindo de forma desarmoniosa diante das leis da natureza. O homem necessita conscientizar-se de que faz parte de um sistema aberto, onde ele é o detentor da inteligência necessária para agir corretamente.

Mas, que significado pode ter a idéia de ecossistema, de estabilidade biológica ou de contaminação ambiental para as imensas massas analfabetas do mundo subdesenvolvido, cuja luta cotidiana e desigual é pela própria sobrevivência em condições precárias e absolutamente hostis? Na realidade, necessitamos não só de uma conscientização ecológica da população mas, também, de uma solução aos problemas socioeconômicos que visea uma vida digna para as populações carentes, principalmente as do meio rural que migram para as cidades em busca de sobrevivência, educando-as e alocando-as em áreas anteriormente dotadas de um planejamento adequado, o que não foi observado até então na cidade 
de Rio Branco com relação à ocupação das margens dos mananciais de água. (BURSZTYN, 1994)

Da mesma forma, Dolffus (1982) diz que a fronteira entre o rural e o urbano torna-se cada vez menos precisa e mais flutuante na sociedade contemporânea. Imprecisa porque é difícil identificar definições exatas e completas e ao mesmo tempo movediça pois o urbano cresce sobre o meio rural. Aqui está a causa principal das agressões ambientais referentes ao manancial de água analisado neste trabalho: o processo de urbanização, com o urbano crescendo sobre o rural quotidianamente.

Resta claro que a transição de uma população rural para urbana, configurando-se no processo de urbanização vigente, é uma das principais responsáveis pela depredação ambiental relacionada aos recursos hídricos, carecendo de planejamento e execução de ações que visem mudanças a curto, médio e longo prazo.

\section{DESCRIÇÃO GEOAMBIENTAL DA ÁREA DE ESTUDO}

O igarapé Judia localiza-se a sudeste do município de Rio Branco, apresentando uma de suas nascentes principais na zona urbana do município de Senador Guiomard/AC e sua desembocadura no bairro seis de Agosto, segundo distrito da cidade de Rio Branco. A nascente principal está localizada entre as coordenadas $10^{\circ} 9^{\prime} 14^{\prime \prime} \mathrm{S}$ e $67^{\circ} 44^{\prime} 14^{\prime \prime}$ W e a desembocadura entre as coordenadas de 958'24" S e 67047'30" W (Figura 1).

$\mathrm{Na}$ zona urbana do município de Rio Branco, após percorrer um trecho na zona rural, o igarapé Judia abrange cinco bairros populacionais, quais sejam: Santa Inês, Mauri Sérgio, Belo Jardim, Seis de Agosto e Santa Terezinha.

Na Figura 1, podemos observar a localização da bacia do Igarapé Judia em pequena escala no Estado do Acre e em grande escala no município de Rio Branco IAC e Senador Guiomard/AC.

É considerado um rio de canal do tipo reto, com pequenos trechos meandrantes, atingindo um índice de sinuosidade de 1,46, considerando-se necessário um índice de sinuosidade igual ou superior a 1,5 para os rios classificados como meandrantes, conforme Christofoletti (1980).

O canal do igarapé Judia percorre um trajeto retilíneo, sem se desviar significativamente de sua trajetória normal em direção à foz. No entanto, observa-se uma tendência ao caráter meândrico com a formação de depressões (pools) e umbrais (riffles) ao longo do leito fluvial. (GUERRA e CUNHA, 2001)

No decorrer do canal, percebe-se uma redução gradativa na declividade do perfil longitudinal, diminuindo com isso a velocidade da corrente de água da montante para a jusante, influindo diretamente na capacidade e competência quanto ao transporte de sedimentos.

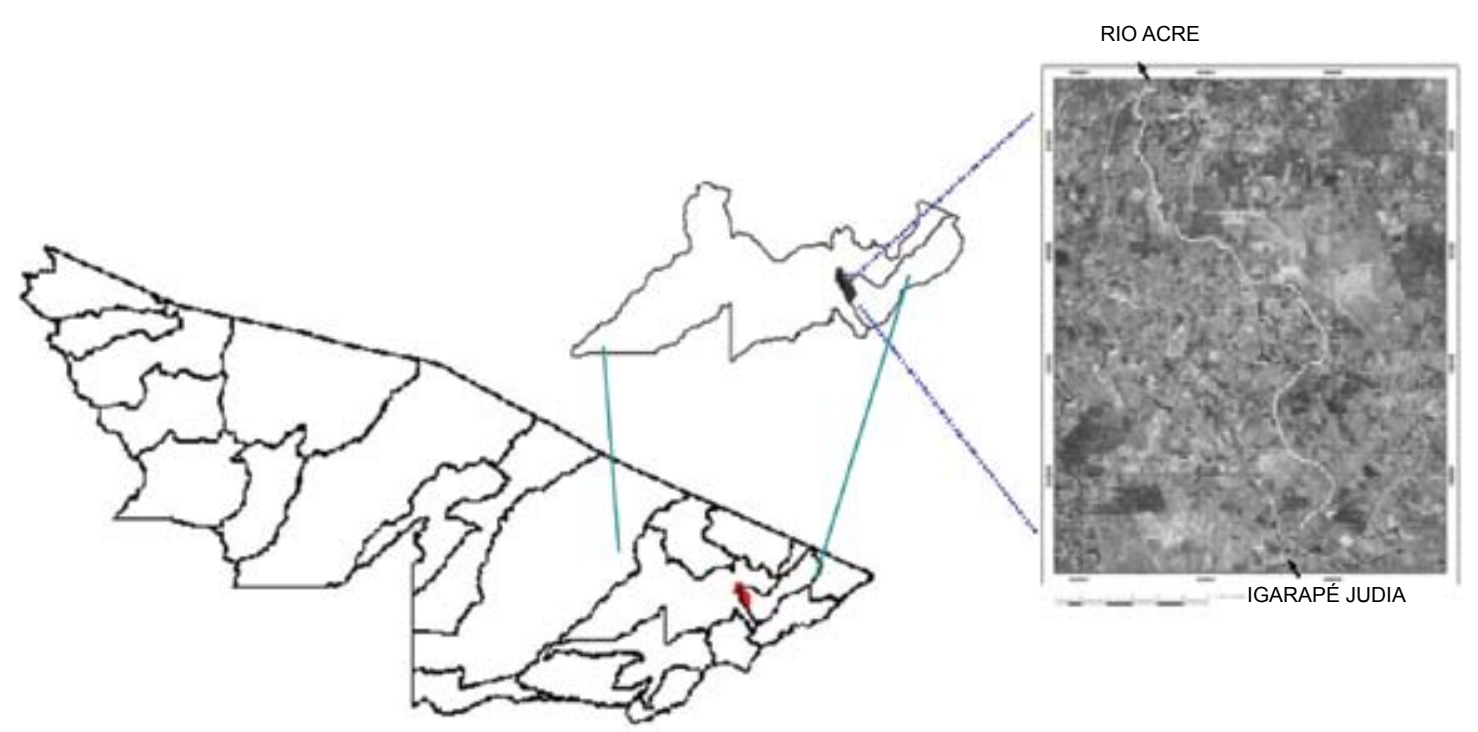

FIGURA 1 - LOCALIZAÇÃO DA ÁREA DE ESTUDOS

FONTE: Imagens cedidas pelo SETEM-UFAC - fevereiro/ 2004 
Por conta disso, faz-se necessário frisar que o igarapé Judia não se encontra em um estado de equilíbrio fluvial, vez que apresenta um alto grau de erosão de suas margens, prevalecendo já em alguns trechos o processo de assoreamento de seu leito. O que se observa é um desequilíbrio no que diz respeito à fluidez de materiais que entram e saem desse sistema fluvial.

O referido igarapé constitui o principal afluente da margem direita do rio Acre, recebendo, ao longo de seu curso de $36 \mathrm{~km}$, carga de sedimentos dos subafluentes Buriti, Almoço, Alagado e Capitão Ciríaco, além de outros pequenos contribuintes de pequena expressão. Classifica-se, de acordo com Horton (1945) apud Guerra e Cunha (2001), de rio insequente, direcionando-se de acordo com a morfologia do terreno e em direção variada, sem nenhum controle geológico aparente, típico de áreas de topografia plana.

A bacia do Igarapé Judia possui uma extensão de $123 \mathrm{~km}^{2}$, sendo classificada como do tipo endorreica, possuindo um padrão de drenagem do tipo dendrítico, característico da região amazônica, desenvolvendo-se sobre rochas de resistência uniforme ou em estruturas sedimentares horizontais. Padrões dendríticos são, provavelmente, os mais comuns para a rede de drenagem, simulando a distribuição ao acaso de partículas d'água em movimento, e indicam a falta de controle estrutural ou a presença de rochas uniformemente suscetíveis à erosão (GUERRA e CUNHA, 2001; BLOOM, 1970).

O igarapé Judia está situado em uma área de relevo de topo pouco convexo, separado por vales em forma de $\mathrm{V}$ e eventualmente por vales de fundo plano, observando-se uma fraca dissecação pelo fato de estar localizado em uma área pouco acidentada, apresentando altitudes em sua nascente de $190 \mathrm{~m}$, local de seu maior gradiente, decaindo em cotas médias de $14 \mathrm{~m}$ ao longo do percurso, apresentando em sua desembocadura uma altitude de $128 \mathrm{~m}$.

A tipologia climática reinante na área é do tipo $\mathrm{Am}$, classificação proposta por W. Köppen, correspondendo a tropical chuvoso (quente e úmido), característico de grande parte da região amazônica.

O igarapé Judia, assim como todos os seus tributários, está localizado em terrenos originários do final do período Terciário e início do Quaternário, sendo constituído de terrenos pliopleistocênicos, onde predominam sedimentos argilosos, areno-argilosos e siltosos.

\section{MATERIAL E MÉTODOS}

Aunidade de estudo abrangida para esta temática foi a faixa urbana da cidade de Rio Branco/AC, constituindo-se dos bairros Santa Inês, Belo Jardim, Mauri Sérgio, Santa Terezinha e Seis de Agosto, todos fazendo parte da APP do igarapé Judia.

Aanálise das condições socioeconômicas e ambientais dos habitantes da APP do igarapé Judia foi realizada em todos os citados bairros da cidade de Rio Branco, onde uma população amostral de 50 moradores, correspondente a 50 imóveis, foi entrevistada sobre questões socioeconômicas e ambientais, bem como suas relações com o curso d'água estudado, no tocante aos usos múltiplos da água.

Para a realização das entrevistas, convencionou-se a visita de um imóvel intercalando-se a cada três imóveis, em cada margem do igarapé. Desse modo, foram realizadas 50 entrevistas de um universo de 194 imóveis, representando $25,8 \%$ do total, percentual este que consideramos representativo para o estudo socioeconômico dos habitantes da área.

Com relação ao diagnóstico da situação socioeconômica e ambiental das famílias que habitam na faixa pertencente à APP, a coleta de dados correspondeu a uma distância de cem metros de ambas as margens do manancial, de acordo com o disposto no art. $2^{\circ}$, alínea "a", n. 3, da Lei n. 4771/65 (Código Florestal brasileiro).

A pesquisa de campo nesse sentido foi do tipo quantitativo-descritivo, com visitas feitas in loco coletando dados com questionários específicos, através de entrevistas padronizadas com perguntas diretas que englobaram aspectos sanitários, condições de moradia, usos múltiplos do curso d'água, tempo de estadia e origem dos habitantes, conforme método proposto por Lakatos e Marconi (1991).

Em cada imóvel visitado, fez-se a anotação do seu ponto de localização através do uso de GPS, e em seguida procedeu-se à plotagem sobre uma fotografia aérea, espacializando as entrevistas e demonstrando a localização das residências na faixa de preservação.

Em seguida, foi gerado um mapa altimétrico da área em estudo, digitalizando-se uma fotografia aérea do ano de 2002, na escala numérica de 1:40000, com o auxílio do software CartaLinx e Idrisi, versão 32 , demonstrando a localização das famílias em áreas de risco de inundação.

\section{RESULTADOS E DISCUSSÃO}

A cidade capitalista constitui, primeiramente, o lugar onde o meio ambiente é caracterizado pela magnitude da segunda natureza; onde a importância da natureza primitiva apresenta-se muito reduzida. Além disso, é o lugar onde o meio ambiente apresenta-se com a mais complexa espacialidade, e esta, por sua vez, constitui uma das bases da realização da sociedade de classes; ao mesmo tempo, de sua reprodução, caracterizando-se 
pela mesma natureza do conteúdo ambiental, quais seja os fixos, fluxos, tipos humanos e sua problematização. (CORRÊA, 1997)

Desse modo e com tal entendimento é que se fundamentou este trabalho, preocupando-se em fornecer subsídios ao poder público no tocante à tomada de decisão em busca do tão sonhado desenvolvimento sustentável na Amazônia, em especial ao na capital do Estado do Acre. Procedeu-se, assim levantamento de dados junto à população que habita as margens do igarapé Judia, no trecho urbano da cidade de Rio Branco, de três importantes variáveis deste pensamento: a social, a econômica e a ambiental.

Para melhor entendimento da ocupação urbana das margens do Igarapé Judia, foi realizada uma plotagem dos pontos marcados com GPS Garmim correspondentes aos imóveis que estão situados naAPP do igarapé Judia, trecho urbano de Rio Branco/AC (Figura 2).

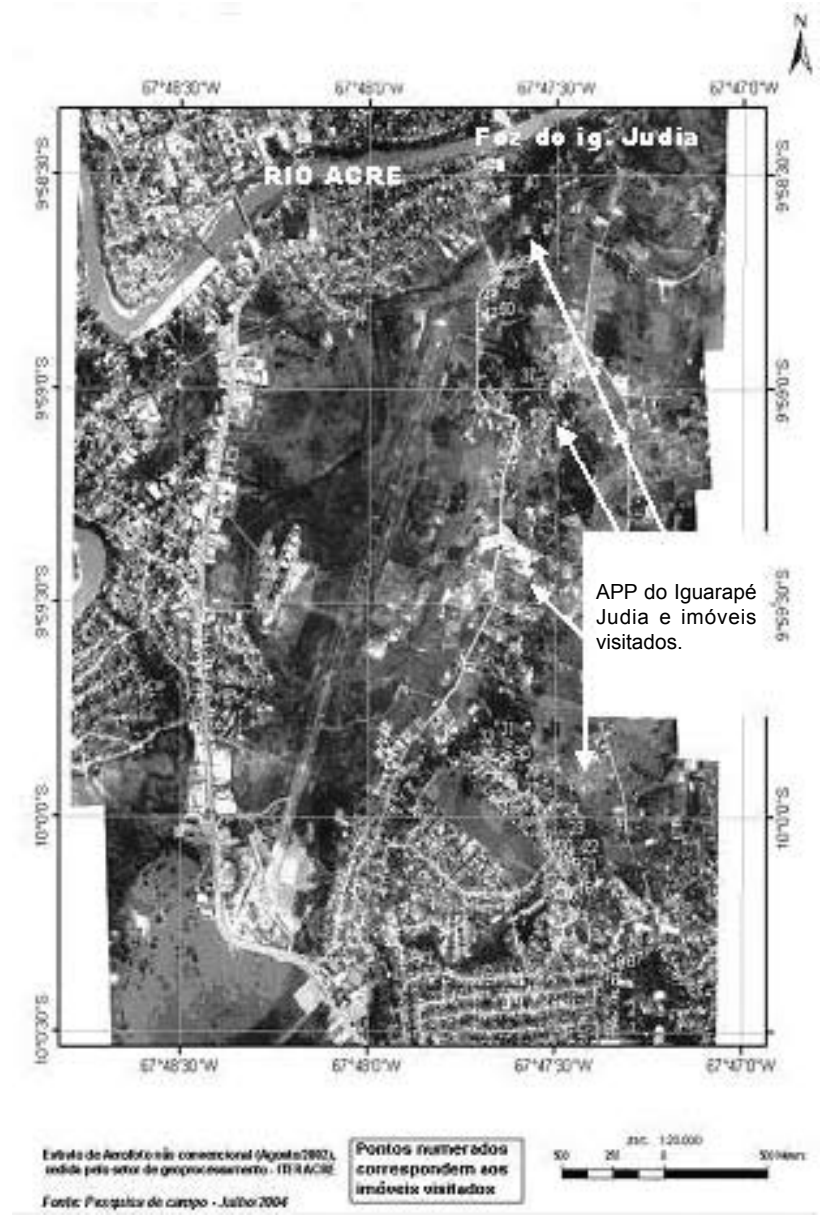

FIGURA 2 - ESPACIALIZAÇÃO DAS ENTREVISTAS

\section{ORIGEM E PROCEDÊNCIA DOS HABITANTES DA ÁREA DE ESTUDO}

Com a pesquisa de campo aplicada junto aos habitantes da área que compreende a APP (Área de Preservação Permanente) do igarapé Judia, houve a preocupação de verificar a procedência dessas pessoas, diagnosticando se eram oriundas da zona rural do município de Rio Branco, de outro bairro da cidade de Rio Branco ou de outro município do Acre ou Estado da Federação.

Com a análise dos dados, verificou-se que $52 \%$ dos habitantes que ali residem atualmente são provenientes da zona rural de Rio Branco, corroborando a idéia de êxodo rural, que há tempos se consolida na capital do Estado do Acre. Ademais, constatou-se que a cidade de Rio Branco tem uma forte migração interna que consiste na saída da população de um determinado bairro para outro, representando $44 \%$ das pessoas que residem hoje às margens do Igarapé Judia. $O$ restante $(4 \%)$ dos habitantes é oriundo de outros Estados, destacando-se o Estado vizinho de Rondônia.

O déficit habitacional de Rio Branco aliado ao desemprego e à falta de oportunidades de renda são os principais motivos que levaram estas pessoas a ocupar, gradativamente, a planície inóspita do igarapé Judia. Em seu bojo, em $56 \%$ da amostragem os entrevistados alegam dificuldades financeiras para adquirir um imóvel em outra área da cidade e, por isso, instalaram-se nas margens desse manancial, seguido de $44 \%$ que alegam não ter outro lugar para moradia a não ser aquela.

Observa-se que a ocupação da APP está intimamente ligada à falta de uma política eficiente de habitação para as pessoas que chegam à cidade, bem como à insuficiência de uma política de geração de emprego e renda aos moradores, fazendo com que estes venham a habitar lugares que correspondem às margens dos mananciais de água, gerando com isso forte degradação ambiental.

Conforme levantamento realizado junto à Fundação Nacional de Saúde (FUNASA), sobre os dados referentes ao número de imóveis e total populacional, localizados nos bairros da cidade de Rio Branco, constatou-se que nos bairros que margeiam o Igarapé Judia há 5.010 imóveis construídos, com uma população de 16.623 habitantes. (Tabela 1) 
TABELA 1 - TOTAL DE IMÓVEIS E POPULAÇÃO RESIDENTE POR BAIRRO DE ABRANGÊNCIA DO IGA RAPÉ JUDIA - RIO BRANCO/AC - 2003

\begin{tabular}{ccc}
\hline BAIRROS & N. DE IMÓVEIS & TOTAL POPULACIONAL \\
\hline Belo Jardim & 919 & 3.676 \\
Mauri Sérgio & 902 & 2.804 \\
Santa Inês & $\mathbf{1 . 6 0 0}$ & $\mathbf{5 . 0 6 4}$ \\
Santa Terezinha & 517 & 1.505 \\
Seis de Agosto & 1.072 & 3.574 \\
\hline Total & $\mathbf{5 . 0 1 0}$ & $\mathbf{1 6 . 6 2 3}$ \\
\hline
\end{tabular}

FONTE: Fundação Nacional de Saúde (FUNASA)-2003

Como se observa na Tabela 1, os bairros de Santa Inês e Seis de Agosto representam a maior ocupação, com 1.600 e 1.072 residências, respectivamente. Além disso, também estão entre os mais populosos; o bairro Santa Inês conta com 5.064 habitantes e o bairro Seis de Agosto, com 3.574. Salienta-se que o bairro Santa Inês possui pouco mais de dez anos recebendo intenso incremento populacional.

Essa área está situada em uma das partes mais baixas da cidade, possuindo uma altitude mínima de $120 \mathrm{~m}$ e máxima de $145 \mathrm{~m}$, representando riscos de inundação e deslizamentos, conforme podemos verificar no mapa altimétrico (Figura 3), com a respectiva plotagem das residências que foram visitadas.

Como se observa na Figura 3, na área de estudo as residências estão localizadas numa cota altimétrica que contraria o disposto na Lei Municipal n. 612, de 19 de junho de 1986, que dispõe sobre o parcelamento e uso do solo na cidade de Rio Branco e, em seu art. 36, inciso IV, determina a não ocupação em terrenos abaixo da cota de $135 \mathrm{~m}$, bem como em faixas de preservação ecológica e da paisagem natural, constituindo-se tal prática em mais um passivo ambiental.

Esta obrigação era estendida a toda a cidade de Rio Branco (AC). No entanto, a Lei Municipal $n^{\circ}$. 1.119, de 11 de outubro de 1993, altera este dispositivo e abre uma exceção para a área de estudo, podendo haver edificações a partir da cota de $132 \mathrm{~m}$, ou abaixo desta cota por interesse do Poder Público, até que fosse feita a reavaliação do Plano Diretor da cidade.

O legislador, com certeza, não tinha o interesse de que algumas das áreas inóspitas da cidade, com referência ao $2^{\circ}$ distrito, tais como nos bairros Santa Terezinha, Santa Inês e Mauri Sérgio, fossem ocupadas com tamanha grandeza da forma como o foram; no entanto, faz 11 anos da promulgação da Lei Municipal n. 1.119/93 e até o momento não tivemos a revisão do Plano Diretor da cidade da forma como ficou estipulado em lei.
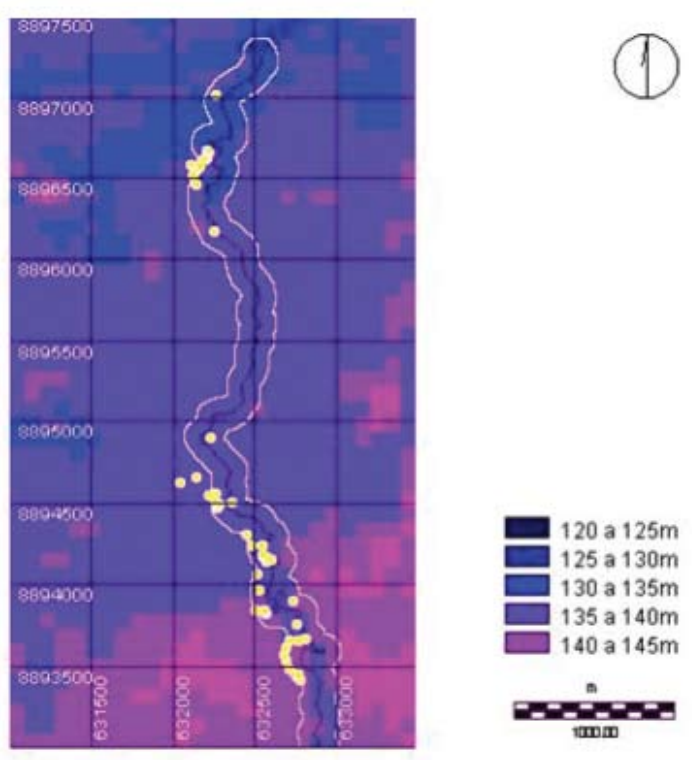

\section{FIGURA 3 - MAPA ALTIMÉTRICO DA ÁREA DE ESTUDO - RIO BRANCOIAC}

FONTE: Digitalizado e elaborado pelo autor - nov. 2004

Portanto, outro entendimento não há senão o de colocar o Poder Público prefeitura municipal como sendo o precursor e próprio permissionário do processo de ocupação das áreas baixas do $2^{\circ}$ distrito da cidade, inclusive às margens dos mananciais de água, causando degradação ambiental e conseqüente queda na qualidade de vida da população.

Embora os bairros Santa Inês, Mauri Sérgio e Belo Jardim sejam oriundos de um processo de invasão de terras, ocorrido há aproximadamente dez anos, apenas $6 \%$ dos primeiros habitantes estão residindo 
nessas áreas, com um tempo de residência de 10 a 14 anos, sendo que a maioria (54\%) dos habitantes reside há apenas três anos nessas áreas.

Tratando-se de áreas desocupadas anteriormente e, conseqüentemente, invadidas posteriormente, observa-se que prevalece no local a chamada "indústria da invasão", 3 onde os primeiros habitantes que procederam à ocupação dessas áreas inicialmente venderam os lotes e, com certeza, grande parte participou de outras invasões de terras na cidade, desencadeando um ciclo de invasões.

Confirmando esta análise, constatou-se que $74 \%$ das pessoas que hoje habitam essa área adquiriram o imóvel através da compra, contra $22 \%$ que realizaram permuta e invasão, e $2 \%$ dos imóveis que foram doados por parentes.

\section{ALFABETIZAÇÃO E OCUPAÇÃO DA MÃO-DE- OBRA NA ÁREA DE ESTUDO}

A partir da análise dos dados (Gráfico 2), constatou-se que a maioria dos habitantes da área em estudo não iniciou ou não concluiu o $1^{\circ} \mathrm{grau}$, atual Ensino Fundamental, representando $86 \%$ dos habitantes entrevistados. Fato de maior descaso e alijamento dessas pessoas do meio social, vez que, não dispondo de

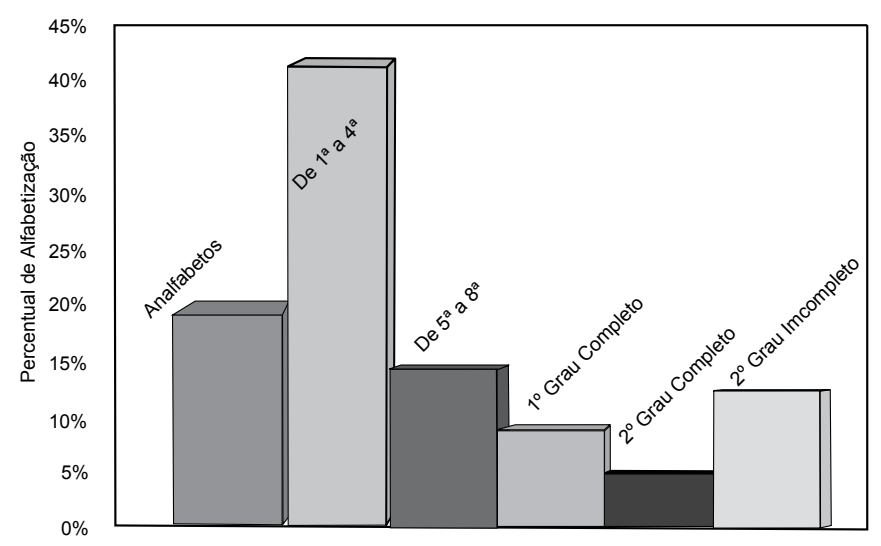

\section{GRÁFICO 2 - NÍVEL DE ALFABETIZAÇÃO DOS HABITANTES DA APP DO IGARAPÉ JUDIA - RIO BRANCOIAC}

FONTE: Pequisa de campo - Jul. 2004 maiores conhecimentos e informação, não conseguem inserção no mercado formal da economia, direcionandose para serviços do setor informal, aumentando a fila da exclusão social na cidade de Rio Branco (AC) e refletindo problemas como falta de emprego e, conseqüentemente, de renda, somados aos problemas sociais advindos dessa exclusão.

Por conta disso, o reflexo da condição de semianalfabetismo existente na área em estudo está presente nos dados que explicitam a ocupação em alguma atividade financeira ou emprego fixo.

É evidente que a deficiência educacional está relacionada intimamente ao emprego, ou não, de determinada parcela populacional. Constatou-se que $58 \%$ dos entrevistados estão em situação de desemprego, não exercendo nenhuma atividade remunerada no setor econômico, e apenas $18 \%$ estão devidamente inseridos no mercado formal da economia, constituindo-se em sua maioria de funcionários públicos.

Tagnin e Magalhães (2001), analisando as questões da qualificação e nível de renda aliada à expansão urbana e proteção dos mananciais na Região Metropolitana do Estado de São Paulo, afirmam que nas experiências brasileiras de proteção aos mananciais, o enfrentamento da expansão urbana mostrou-se desafiador, vez que se dispõe de recursos reduzidos para elevadas demandas de baixa renda. Excetuando-se a cidade de Belo Horizonte, que impediu a ocupação e reorientou o seu crescimento para longe dos mananciais, os demais casos brasileiros toleraram a expansão urbana, sem observar que um grande contingente populacional estava se direcionando para essas áreas.

A cidade de Rio Branco, desde a sua origem até o presente, acompanhou essa tendência e tem sido palco de transformações contínuas que vão desde a sua ocupação recente, com o aparecimento de vários bairros sem um plano de desenvolvimento adequado às realidades dos seus ocupantes e recém-chegados, até a total desconfiguração da paisagem urbana, que é vista e diagnosticada através da freqüente luta de classes que ocorre no seio da sociedade, angariando a sua sobrevivência.

Esses momentos de mudança vieram a elevarse, a partir da década de 1970, quando da desativação dos seringais nativos da região e conseqüente saída de grande parte da população do campo para as cidades.

30 termo denota a condição econômica das pessoas que procedem a um processo invasivo de terras. No entanto, elas não necessitam dessas áreas e as vendem por um preço abaixo do observado no mercado imobiliário, angariando, assim, alguma renda. Não há que esquecer que, muitas vezes, isso ocorre em forma de expropriação das famílias pelo capital imobiliário. Tal procedimento tornou-se uma constante na cidade de Rio Branco nas décadas de 1980 e 1990, prática que atinge principalmente as famílias de classe baixa e desempregada. 
Há que se ter em mente que organizar o espaço não somente é colocar cada peça que compõe o todo em seu devido lugar, mas sim traçar estratégias que visem à harmonia entre essas peças. Tal fato não se observa plenamente em Rio Branco (AC).

A cidade possui um Plano Diretor de Desenvolvimento Urbano ${ }^{4}$, no entanto este não foi colocado em prática em sua plenitude dada a fragilidade do poder público em fazer cumpri-lo. Dispositivos como a Lei de Uso e Parcelamento do Solo Urbano ${ }^{5}$ e o Código de Posturas da Cidade $^{6}$, uma vez cumpridos, diminuiriam muitos problemas de organização espacial.

Como toda cidade em vias de crescimento, Rio Branco sofre com o caso da elevação do número de pessoas inseridas em atividades informais, fazendo surgir visivelmente a importância do setor terciário no meio urbano.

Esta análise é válida no presente trabalho, uma vez que $20 \%$ das pessoas que residem na APP do igarapé Judia estão ocupadas nas atividades informais, carecendo de tomadas de decisões que visem ao aproveitamento dessa mão-de-obra em atividades formais do poder público ou iniciativa privada, a começar por sua inclusão no ensino público gratuito e de qualidade.

A maioria das pessoas que exercem as atividades informais está localizada em áreas periféricas da cidade, sendo, portanto, mais um fundamento para afirmarmos que essas atividades constituem a saída para a sobrevivência das pessoas de baixa renda, ou sem renda alguma, sendo habitantes de localidades que detêm pouca ou quase nenhuma infra-estrutura instalada e, portanto, carentes da assistência pelo poder público.

O levantamento das características econômicas da população residente na área em estudo torna-se necessário, vez que toda tentativa de modificação estrutural nessa área deve ser seguida da idéia de sustentabilidade, abrangendo-se, igualmente, entre as demais variáveis (sociais, culturais e ambientais) a variável econômica.

Tal levantamento fez parte da pesquisa de campo desenvolvida na APP do igarapé Judia, e, da análise dos dados, observou-se que $56 \%$ dos habitantes que residem na área percebem pouco mais de um salário mínimo mensal ${ }^{7}$, seguido de $24 \%$ que têm uma renda mensal menor que um salário mínimo, vivendo praticamente abaixo da linha de pobreza, instituída pela Organização das Nações Unidas aos países emergentes.

Verificou-se que, na área em estudo, muitas pessoas vivem com dificuldades para comprar o básico ao sustento da família, vivendo com total carência de recursos. Na Tabela 5 estão expostos os dados referentes ao nível de renda estipulado em salários mínimos para a população que habita aquela região.

\section{SERVIÇO DE ÁGUA, ESGOTO E COLETA DE LIXO NA ÁREA DE ESTUDO}

Os imóveis que fizeram parte da pesquisa não dispõem, em sua totalidade, do serviço de água encanada, tampouco de rede de esgoto instalada. Tais serviços, que são de fundamental importância para a qualidade de vida da população, não se fazem presentes em nenhum dos imóveis visitados.

Diante disso, procurou-se identificar a origem da água consumida pelos habitantes da área, diagnosticando-se que $88 \%$ dos entrevistados consomem água de poço; em contrapartida, $12 \%$ utilizam a água do igarapé para beber, cozinhar e as demais atividades diárias.

Quanto à forma encontrada para despejo dos esgotos produzidos nos imóveis, a pesquisa constatou um fato preocupante, revelando que $80 \%$ dos imóveis da área em estudo destinam seus dejetos para o leito do igarapé Judia e apenas $20 \%$ os destinam para fossas. Tal fato exige ainda mais para uma tomada de decisão que vise à implantação de políticas públicas para a área, no intuito de minimizar essas práticas.

Um dos itens que representam a qualidade de vida de uma população é a coleta regular de lixo. $\mathrm{Na}$ área em estudo, a coleta abrange $52 \%$ das residências; o restante não é servido com a coleta.

No entanto, nos imóveis que não dispõem deste serviço, $54,2 \%$ queimam os detritos produzidos, adotando a prática das pequenas queimadas urbanas que

4 É válido lembrar que o $1^{\circ}$ Plano de Diretor de Desenvolvimento Urbano de Rio Branco - $1^{\circ}$ PDDU - data do ano de 1986 , há 18 anos, e que ainda hoje é válido e não vem sofrendo modificações e adequações necessárias paralelamente às transformações da cidade e, na maioria das vezes, não vem sendo cumprido.

5 Trata-se da Lei Municipal n. 612, que também foi instituída em 1986 pelo município de Rio Branco. Corresponde a um dos mais importantes instrumentos legais de adequação das construções e ocupação do espaço urbano, mas, com o passar do tempo, também não foi observado e cumprido em sua plenitude.

6 Relaciona-se à Lei Municipal n. 163, instituída em 1973 pelo município de Rio Branco, e também traz em seu bojo uma importante contribuição para a adequação das atividades, apresentando normas de interesse público concernentes à higiene e saúde, abastecimento e ordenamento das atividades urbanas. Nesse momento (1973), a cidade de Rio Branco estava recebendo grande fluxo de migrantes, principalmente da zona rural do município, fazendo com que o legislador oportunamente pensasse em instituir tal lei; no entanto, é apenas mais uma que, quase sempre, passou despercebida nas ações de fiscalização do poder público.

$7 \mathrm{Na}$ época da pesquisa de campo, o salário mínimo no Brasil correspondia a $R \$ 260,00$ (duzentos e sessenta reais). 
são freqüentes na cidade de Rio Branco. O percentual de $16,6 \%$ depositam o lixo na rua e, como não há coleta, esse lixo é carreado para as partes mais baixas do terreno, formando grandes depósitos de detritos.

O fato mais preocupante é que o lixo produzido em $29,2 \%$ dos imóveis é deposita nas margens e no leito do igarapé Judia, aumentando a degradação e a poluição na área. Esse número reflete as condições sanitárias em que vivem as pessoas daquela área. Sem uma educação ambiental eficiente e com a falta do serviço de coleta de lixo regular, depositam os dejetos diretamente no lgarapé, destruindo-o lentamente (Gráfico 3).

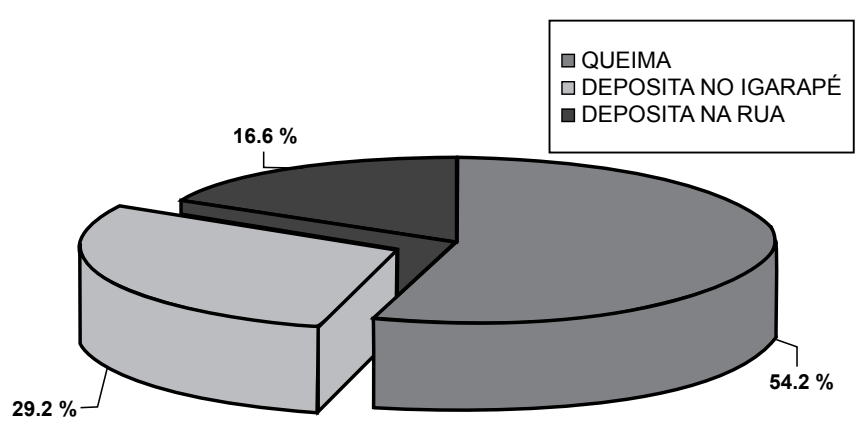

\section{GRÁFICO 3 - DESTINO DO LIXO PRODUZIDO NOS IMÓVEIS DA APP DO IGARAPÉ JUDIA - RIO BRANCOIAC}

FONTE: Pesquisa de campo - Jul. 2004

Torna-se claramente visível o descaso com que é tratado o Igarapé Judia pelos habitantes da área, evidenciando-se nos dados acima que a degradação ambiental dos mananciais, não só na cidade de Rio Branco como também nos grandes centros do País, é provocada pela dissociação sociedade versus natureza e cidade versus natureza, culminando com os conflitos e impactos ambientais que ocorrem nestas áreas, tais como:

- ausência ou deficiência nos serviços de coleta e tratamento de resíduos sólidos e líquidos;

- concentração da degradação dos recursos ambientais, principalmente a poluição do ar, do solo e das águas;

- ocupação de áreas de risco por diversas atividades humanas;

- arruamento e pavimentação potencializando processos erosivos, com ravinas e voçorocas instalando-se em ruas e nos fundos de vales, principalmente nas periferias pobres;
- cursos d'água e fundos de vale transformados em depósitos de lixo, escoadouros de esgotos e locais de residências precárias;

- assoreamento dos cursos d'água;

- disseminação de doenças infectocontagiosas provocadas pela degradação do meio ambiente;

- alienação da população pobre sobre a origem e o destino das águas que abastecem suas moradias (LEAL e HERMANN, 1999).

\section{USO MÚLTIPLO DAS ÁGUAS E CONTRAÇÃO DE DOENÇAS}

A população que faz parte da área de estudo utilizase de alguma forma da água do igarapé Judia. Nesse sentido, e pela já verificada falta de infra-estrutura no local, inserimos na pesquisa junto aos moradores questões relativas ao uso que fazem do igarapé.

Dos imóveis visitados, diagnosticou-se que $40 \%$ das pessoas utilizam o igarapé para a prática do banho, por não ter outro local para tal, contra $38 \%$ que utilizam as águas para lavar roupas e louças.

Em virtude da falta de água tratada, que deveria ser fornecida pelos órgãos governamentais, por ser um dever do Estado, $8 \%$ dos habitantes da área usam a água do igarapé para beber, $10 \%$ para cozinhar e $12 \%$ para pescar e angariar o sustento da família. Em contrapartida, $40 \%$ não utilizam a água do igarapé, fazendo parte do percentual que tem o poço para abastecimento d'água. (Gráfico 4)

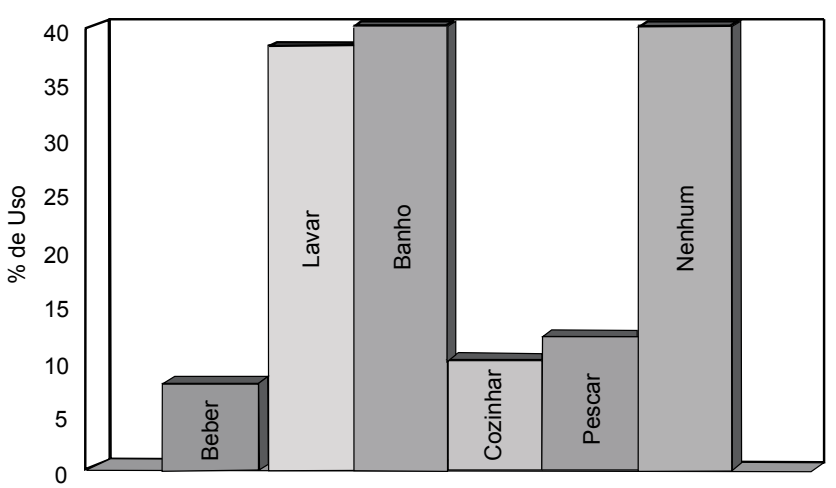

GRÁFICO 4 - TIPOS E PERCENTUUAL DE USOS MÚLTIPLOS DA ÁGUA DO IGARAPÉ JUDIA - RIO BRANCOIAC

FONTE: Pequisa de campo - Jul. 2004 
Portanto, verifica-se que não possuindo outra saída as pessoas ainda têm no igarapé Judia a esperança de sobrevivência, pelo seu uso nas mais diversas atividades diárias. Este sem dúvida é o grande eixo motivador para que haja a conservação deste manancial, que é de suma importância na vida das pessoas que habitam suas margens.
Na Figura 4, podemos observar a pesca no igarapé Judia em época de cheia, representando a alimentação de famílias que não têm o que comer ou fonte renda, buscando naquele manancial a saída para a sobrevivência.

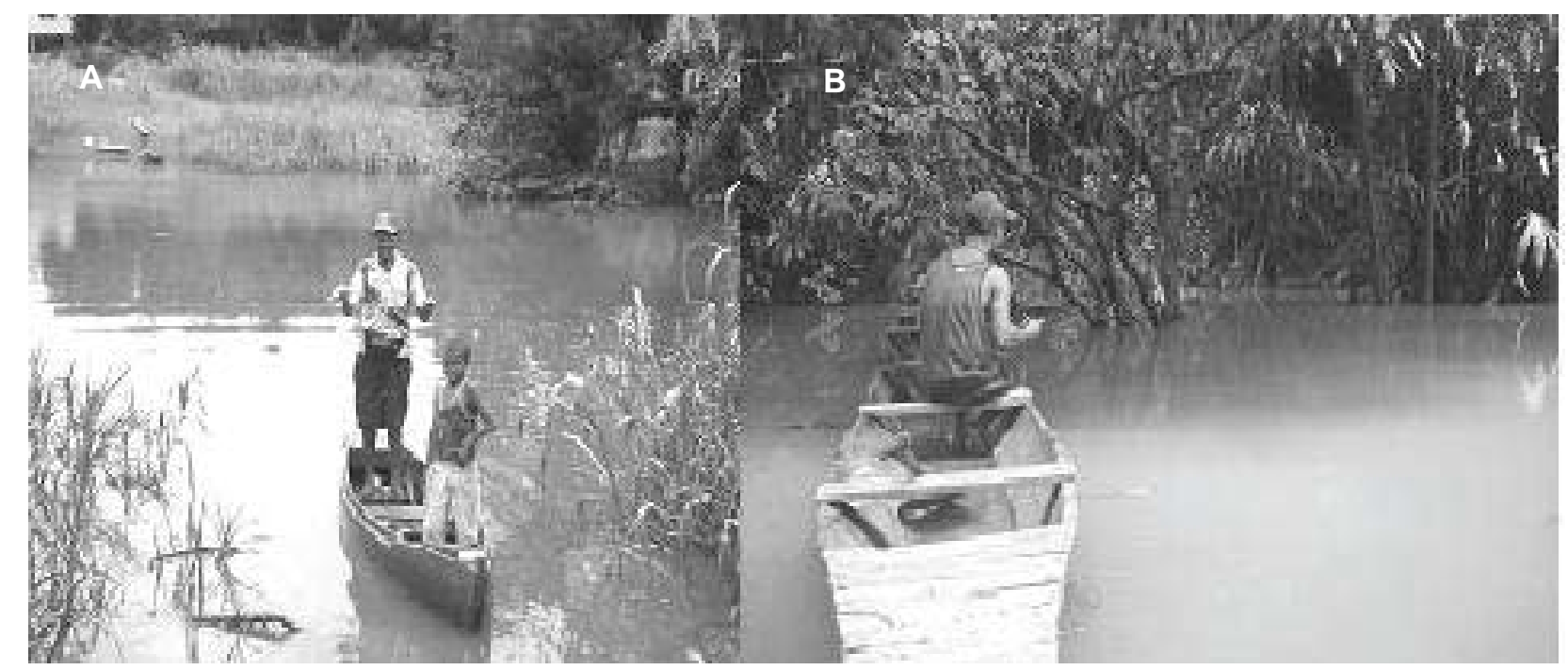

\section{FIGURA 4 - ATIVIDADE PESQUEIRA NO IGARAPÉ JUDIA}

No detalhe da foto $A$, o pescador mostra o resultado da pescaria nas águas do igarapé Judia em época de cheia. Na foto $B$, a pesca aumenta a esperança do que comer, demonstrando em ambas as imagens que ainda é possível contar com aquele manancial para a sobrevivência.

FONTE: Foto/Arquivo do autor - Jan. 2004

O uso do igarapé sem uma fiscalização eficiente coloca em risco toda a vida aquática ali existente, uma vez que tal uso se confunde com diversas atividades, desde a deposição de esgoto e lixo, considerandose um grande lixão em determinados pontos, até a lavagem de produtos domésticos, tais como louças e roupas, com o conseqüente escoamento de detergentes.

A utilização da água reflete na saúde das pessoas. Como vimos acima, o esgoto e o lixo aliados à falta de infra-estrutura de saneamento básico têm destino certo - o leito do igarapé -, tornando-se uma ameaça à vida aquática num primeiro momento $e$, num segundo momento, uma ameaça à própria vida humana.

$\mathrm{Na}$ presente pesquisa, procuramos identificar as principais doenças que as pessoas da localidade têm contraído no último ano antecedente à pesquisa, diagnosticando que $24 \%$ delas contraíram malária, $14 \%$ tiveram hepatite, seguidos de $12 \%$ que contraíram algum tipo de micose, além do percentual de $8 \%$ que tiveram diarréia e dengue.

\section{USO DA TERRA NA ÁREA DE ESTUDO}

O igarapé Judia apresenta um escoamento natural que transporta grande quantidade de material em suspensão e dissolvido, tendo origem o processo erosivo das suas margens pela grande quantidade de resíduos domiciliares que são lançados em seu curso ao longo de sua extensão, devido à ocupação humana que se apresenta em sua planície de inundação.

Tal ocupação é registrada já na sua nascente principal, no município de Senador Guiomard (AC), sem haver a preocupação de conservá-la ou preservála, apresentando uma área já bastante antropizada e degradada, inclusive, de fundos com grandes chácaras que fazem, no início do igarapé Judia, barragens para a formação de açudes, conforme se observa na Figura 5 , alterando bruscamente o ciclo de vida do igarapé.

No meio curso do igarapé Judia, é notável a presença de propriedades que margeiam esse manancial, com unidades habitacionais construídas, cujos dejetos são carreados para o leito do igarapé. 
Nessas propriedades, o desmatamento já é uma constante, apresentando capoeira em formação e plantação de algumas culturas, como arroz, mandioca e milho, além da criação de bovinos, ambos na planície de inundação.

A ocupação desenfreada das margens e o uso da terra na área de abrangência desse manancial estão afetando sobremaneira a cobertura vegetal original da área uma vez que, para plantar, os moradores necessitam desmatar e, posteriormente, proceder à queima da vegetação, como é costume na região.

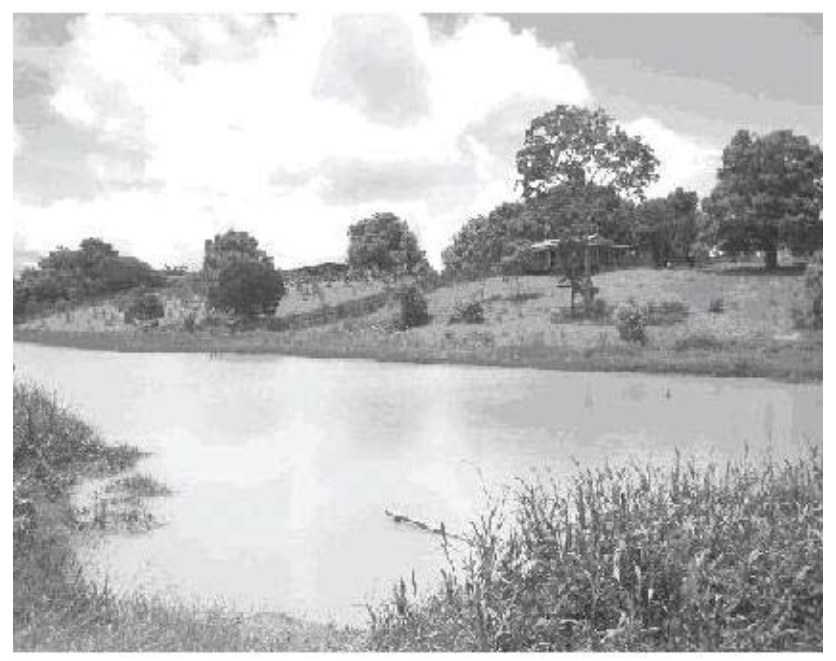

FIGURA 5 - AÇUDE FORMADO NO LEITO DO IGARAPÉ JUDIA - SENADOR GUIOMARDIAC

As barragens já fazem parte do cotidiano do Igarapé Judia e, no caso acima, faz fundos com grandes chácaras que estão situadas no curso superior, próximas à sua nascente principal, no centro da cidade de Senador Guiomard/AC, recebendo dejetos domiciliares, alterando significativamente o ciclo de vida do Igarapé e diminuindo a vazão nos cursos inferiores.

FONTE: Arquivo do autor - Jan. 2004

Aliado a isso, apresenta-se ao longo do trecho que compreende o igarapé a prática da criação de bovinos, com conseqüências desastrosas ocasionando a degradação do solo e os processos erosivos das margens do igarapé, dado o intenso pisoteio do gado (Figura 6).
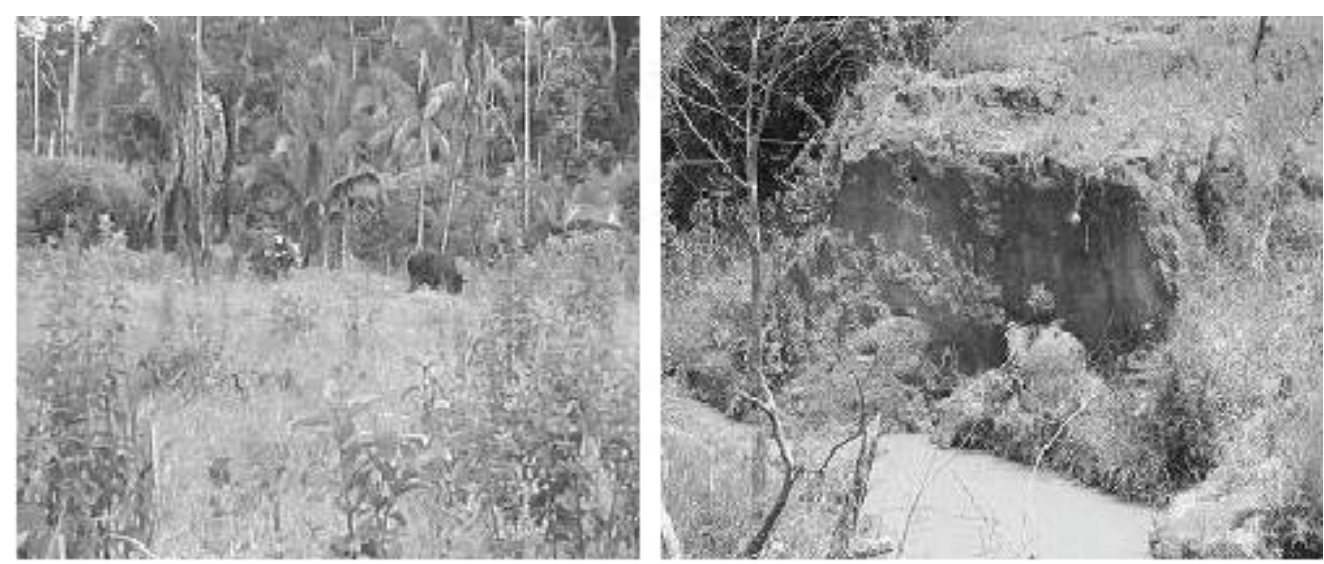

\section{FIGURA 6 - A PRÁTICA DA CRIAÇÃO DE BOVINOS ÀS MARGENS DO IGARAPÉ JUDIA - RIO BRANCO / AC}

Com a retirada da mata ciliar para a plantação de capim e criação bovina, o igarapé Judia sofre com o assoreamento de seu leito, dada a erosão das margens em conseqüência do pisoteio do gado, que, além de compactar o solo e frear o crescimento natural da vegetação, faz com que a erosão ocorra freqüentemente.

FONTE: Arquivo do autor - Jan. 2004 
Na parte que compreende o curso inferior do igarapé Judia, a problemática é ainda mais dramática, uma vez que essa área é receptora de toda a carga poluidora que o manancial recebe ao longo de seu curso. Ali a poluição torna-se mais evidente, em razão do alto grau de urbanização na área, apresentando residências que estão situadas na margem do igarapé, com o despejo in natura de esgoto e lixo, ameaçando de extinção a vida existente nesse manancial (Figura 7).
Em Rio Branco (AC), o igarapé Judia recebe a maior carga de poluentes em seu leito devido às construções em sua planície de inundação e ao despejo de dejetos domiciliares cotidianamente observado. Com isso, tanto a vida do igarapé está ameaçada como também a vida dos próprios habitantes dessas áreas, que utilizam a água para beber, lavar, tomar banho ou para práticas agrícolas de subsistência.

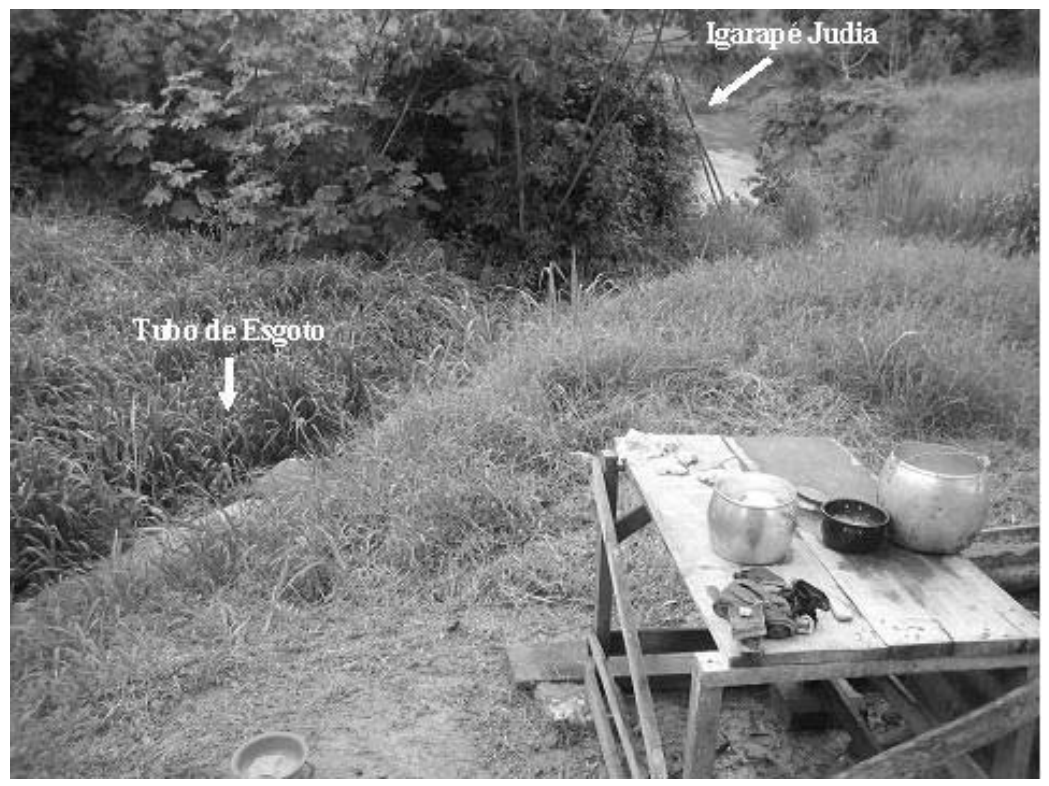

\section{FIGURA 7 - CANALIZAÇÃO DE ESGOTO DOMÉSTICO PARA O LEITO DO IGARAPÉ JUDIA}

A canalização de esgotos domésticos e a retirada da mata ciliar, já no curso inferior do Igarapé Judia, em Rio Branco, é realizada sem precedentes. O principal motivo dessa ocorrência é a falta de implantação de infra-estrutura nos bairros que abrangem o igarapé aliada à falta de fiscalização do poder público.

FONTE: Arquivo do autor - Jan. 2004

TABELA 2 - TIPOS DE CULTIVOS PLANTADOS NA APP DO IGARAPÉ JUDIA - RIO BRANCOIAC

\begin{tabular}{ccc}
\hline No $^{\circ}$ & Tipo de Cultura & \% de Ocorrências \\
\hline 1 & Mandioca & 46,6 \\
2 & Banana & 33,3 \\
3 & Abacaxi & 20,0 \\
4 & Cupuaçu & 13,3 \\
5 & Milho & 13,3 \\
6 & Feijão & 6,6 \\
7 & Mamão & 13,3 \\
8 & Caju & 6,6 \\
9 & Laranja & 6,6 \\
10 & Hortaliças & 6,6 \\
\hline
\end{tabular}

FONTE: Pesquisa de campo - Jul. 2004
No entanto, com o intuito de fornecer subsídios ainda mais eficientes para o planejamento do uso da terra na área de estudo, tivemos a preocupação de investigar se os habitantes praticam a plantação de alguma cultura e quais os tipos de produtos cultivados nos imóveis visitados.

Com a pesquisa de campo realizada nos imóveis do trecho urbano da cidade de Rio Branco, obtivemos os seguintes dados, conforme Tabela 2.

Praticamente todos os cultivos na área são irrigados com águas do igarapé Judia. Conforme se observado nos dados apresentados acima, a mandioca está presente em $46,6 \%$ dos imóveis que praticam algum tipo de cultura, assumindo posição de destaque entre as demais. Vale ressaltar que há estabelecimentos que plantam dois ou mais tipos de produtos simultaneamente. 
Diante desses dados, observa-se uma variedade de produtos que são cultivados na APP do igarapé Judia; no entanto, somente $30 \%$ dos imóveis visitados praticam algum tipo de plantação, contra $70 \%$ que não têm hábito dessa prática.

\section{CONSIDERAÇÕES FINAIS E RECOMENDAÇÕES}

Como explicitado ao longo do texto, a APP do igarapé Judia $(A C)$ apresenta vários problemas de ordem estrutural devido ao adensamento populacional nessa região, carecendo de medidas corretivas e punitivas para evitar que outras áreas sejam também afetadas pelo fenômeno da urbanização.

Como fundamento nas idéias apresentadas, remetemo-nos ao aumento significativo dos índices populacionais como fator de transformação das condições ambientais até então observados no estado do Acre e, em especial, nos municípios de Rio Branco e Senador Guiomard.

Nesse toar, apresentamos uma problemática atual nas médias e grandes cidades do país e que, sem exclusão, hoje é motivo de preocupação também na cidade de Rio Branco/AC - a questão da urbanização e a degradação dos mananciais de água -, obtendo como estudo de caso o igarapé Judia, que vem apresentando, ao longo de quatro décadas, constante ocupação e urbanização de sua APP, exercendo pressão negativa sobre a qualidade ambiental dessa região.

Através do levantamento socioeconômico realizado com os habitantes da APP estudada, constatou-se que as condições financeiras de uma vasta camada populacional, aliadas às ineficientes políticas públicas de habitação, evidenciam a ocupação de áreas inóspitas à moradia na cidade.

Nesse sentido, ao ocupar essas áreas, a grande massa populacional ocasiona um dano duplo. Primeiro, porque há um dano ambiental quando direciona toda a carga de esgoto doméstico in natura e grande parte do lixo produzido para o leito do igarapé Judia; e, segundo, quando o resultado da primeira prática atua sobre a saúde da própria população que faz uso daquele manancial diariamente, ocasionando assim um dano social.

A competição pelo uso diversificado ocasionou o aumento da degradação dos recursos hídricos em Rio
Branco/AC, através da deposição de lixo e da emissão in natura de esgotos não tratados nos mananciais de água.

Como forma de amenizar a pressão humana exercida sobre aquele manancial, sugere-se algumas medidas que deverão ser tomadas a curto, médio e longo prazo, no intuito também de melhorar a qualidade ambiental daquela região.

\section{Curto prazo}

- Proceder, de início, uma ampla campanha educacional sobre a importância do igarapé para os habitantes da cidade.

- Recomenda-se a desobstrução de pontos que se encontram com entulhos (lixo), bem como a retirada de cercas e unidades sanitárias (latrinas) presentes nas margens do igarapé.

\section{Médio prazo}

- Reorientar a expansão urbana para fora da área dos mananciais, visando a proteção e a conservação dos mesmos.

- Proceder ao cumprimento da Lei de Uso e Parcelamento do Solo Urbano, de modo a conter a invasão de áreas que fazem parte da APP da bacia hidrográfica do igarapé Judia, no Acre.

\section{Longo prazo}

- Proceder a possível desocupação e o isolamento da área que, legalmente, faz parte da APP, fundamentando-se no Código Florestal brasileiro.

- Difundir uma política de reflorestamento para a totalidade da bacia do igarapé Judia, no Acre.

Com o diagnóstico dos impactos ambientais ocorrentes na APP do igarapé Judia, fica evidente que a preocupação com as práticas de conservação e preservação dos cursos d'água que fazem parte da imensa bacia amazônica deve ser quotidiana, carecendo de ações de educação ambiental que visem, acima de tudo, cessar a destruição dos ecossistemas aquáticos. 


\section{REFERÊNCIAS}

ALMEIDA, J. R. de et al. Planejamento ambiental: caminho para participação popular e gestão ambiental para nosso futuro comum: uma necessidade, um desafio. 2. ed. Rio de Janeiro: Thex Ed: Biblioteca Estácio de Sá, 1999.

BLOOM, A. L. Superfície da Terra. São Paulo: E. Blücher, 1970.

BRASIL. Lei Federal n. 4.771/65, institui o Código Florestal Brasileiro, 1965.

BURSZTYN, M. Para pensar o desenvolvimento Sustentável. 2. ed. São Paulo: Brasiliense. 1994.

CHRISTOFOlETTI, A. Geomorfologia. São Paulo: E. Blücher, 1980.

CORREAA, R. L. Trajetórias geográficas. Rio de Janeiro: Bertrand Brasil, 1997.

DOLFFUS, O. O espaço geográfico. São Paulo: Difusão, 1982.

FUNDAÇÃO NACIONAL DE SAÚDE - FUNASA. Quantitativo Populacional. Rio Branco: CCGE, 2003.

GARAY, I. E. G.; DIAS, B. F. S. Conservação da biodiversidade em ecossistemas tropicais: avanços conceituais e revisão de novas metodologias de avaliação e monitoramento. Petrópolis: Vozes, 2001.

GUERRA, A. J. T.; CUNHA, S. B. da (Orgs.). Geomorfologia: uma atualização de bases e conceitos. Rio de Janeiro: Bertrand Brasil, 2001.
INSTITUTO BRASILEIRO DE GEOGRAFIA E ESTATÍSTICA - IBGE. Censo Demográfico. Rio de Janeiro: IBGE, 1970. . Censo Demográfico. Rio de Janeiro: IBGE, 1980. . Censo Demográfico. Rio de Janeiro: IBGE, 1990. . Censo Agropecuário. Rio de Janeiro: IBGE, 1996. . Censo Demográfico. Rio de Janeiro: IBGE, 2000. Censo Demográfico (Dados Preliminares). Rio de Janeiro: IBGE, 2003.

LAKATOS, E. M.; MARCONI, M. de A. Fundamentos de metodologia científica. São Paulo: Atlas, 1991.

MAGALHÃES, J. P. Recursos naturais, meio ambiente e sua defesa no direito brasileiro. Rio de Janeiro: FGV, 1982.

PIAGET, J. O estruturalismo. Rio de Janeiro: Difel, 1979.

RIO BRANCO. Prefeitura Municipal. Lei Municipal n. 163/73, institui o Código de Posturas da Cidade, 1973.

Lei Municipal n. 612/86, institui o Uso e Parcelamento do Solo Urbano, 1986.

Lei Municipal n. 1.119/93, altera a cota altimétrica da cidade de Rio Branco, 1993.

STEVENSON, W. J. Estatística aplicada à administração. São Paulo: Harper \& Row do Brasil, 1981.

TAGNIN, R. A.; MAGALHÃES, E. de W. O tratamento da expansão urbana na proteção aos mananciais: o caso da Região Metropolitana de São Paulo. São Paulo: EDUSP, 2001. 